\title{
Creating Opportunities for Social Change in Women's Sport Through Academic and Industry Collaborations: An Interview With Kate Fagan
}

\author{
Nefertiti A. Walker and E. Nicole Melton \\ University of Massachusetts-Amherst
}

\begin{abstract}
A number of scholars have articulated the real and perceived benefits of engaging in collaborations with practitioners and have urged researchers to establish industry partnerships. Much of the discussion, however, stems from a researcherperceptive and focuses on developing theory and scholarly advancements; less effort has been made to understand the potential advantages from a practitioner's viewpoint. Therefore, this paper uses an expert interview methodology to explore the industry perspective. Through an interview with Kate Fagan, an espnW and ESPN.com journalist, this article sheds light on how academic researchers and sport industry professionals, particularly those working in women's sports, can collaborate and produce rich data and stories supporting social change. In addition, the authors provide suggestions for establishing a productive relationship among the sport industry and academia.
\end{abstract}

Keywords: industry collaborations, social change, sport media, women's sport

Research over the past 30 years reliably shows female athletes and women's sports routinely receive blatant disparate treatment by the sports media compared with male athletes and men's sports (for a review see Fink, 2014). This differential treatment manifests in two ways: the amount of media coverage women are afforded, and the ways female athletes and women's sports are represented in the sports media. With respect to the former, researchers have demonstrated (in a variety of contexts) that female athletes receive significantly less coverage than male athletes in written media (Kian, Vincent, \& Mondello, 2008; Lumpkin, 2009), broadcast media (Caple, Greenwood, \& Lumby, 2011; Cooky et al., 2013), and new forms of media (Burch, Eagleman, \& Pedersen, 2012; Clavio \& Eagleman, 2011; Kian, Mondello, \& Vincent, 2009). In fact, coverage of women's sports has actually declined over the years despite increases in participation and greater

The authors are with the McCormack Department of Sport Management, Isenberg School of Management, University of Massachusetts-Amherst, Amherst, Massachusetts. Address author correspondence to Nefertiti A. Walker at nwalker@isenburg.umass.edu. 
athletic performance (Cooky et al., 2013; Kane, 2013). The manner in which the sport media represents female athletes and women's sports is perhaps even more concerning than the overall lack of coverage. Indeed, past research demonstrates that differences in production techniques and sportscaster commentary tends to cast women's sports as insignificant or less exciting compared with men's sports (Entman, 1993; Greer, Hardin, \& Homan, 2009).

In addition, media portrayals of female athletes rarely focus solely on their athletic accomplishments; instead, the focus is often on, physical appearance, femininity, or heterosexuality. Fink (2014) contends that "these practices are so pervasive, and they have become so deeply woven into the fabric of the marketing and production of women's sport, that most consumers do not notice, let alone question, their insidious nature" (p. 3). It is indeed regrettable that people thoughtlessly accept sports media's representation of women's sports, as exposure to these media frames and depictions of female athletes relates to objective appraisals of athletes among adolescent boys (Daniels \& Wartena, 2011), reinforces gender stereotypes in sport (Angelini, 2008), lower perceptions of athletic expertise and respect for the athletes' accomplishments (Fink, 2010). Thus, the sports media's minimal coverage of women's sports coupled with the disparagingly different way it portrays female athletes, continues to reinforce male power and privilege within sport.

Though scholars continue to document the adverse effects of differential coverage, most sports media seemingly ignore research findings and continue to trivialize the accomplishments and athleticism of female athletes. However, there are some encouraging signs of change. For instance, the launch of espnW created a space devoted to covering women's sports and celebrating the accomplishments of female athletes. In addition, more journalists_-particularly those who work for espnW-are challenging traditional notions of women's sport through the topics they investigate and stories they write.

Fink (2014) contends scholars can also contribute to creating change in women's sport-even though it may seem that their work fails to produce a meaningful impact in the industry. Specifically, she suggests that one way to ensure academic research influences decision makers is to develop collaborative partnerships with sport organizations. A number of scholars support Fink's contention and have also called for greater collaboration between academia and industry (e.g., Cunningham, 2012; Fink, 2013; Frisby, Reid, Millar, \& Hoeber, 2005; Irwin \& Ryan, 2013; Van de Ven, 1989). To date, much of the discussion has focused on how scholarpractitioner relationships can make research more accessible, generate relevant questions, inform practice, and advance theory development. Interestingly, though scholars articulate the benefits of partnerships and urge researchers to engage in collaborative forms of inquiry, there is less understanding of how to establish meaningful relationships. Furthermore, arguments for cross collaborations typically stem from a researcher perspective, and do not always account for and incorporate the thoughts and opinions of industry professionals. This omission is unfortunate, as understanding the practitioner perspective may shed new light on how to create mutually beneficial partnerships.

The purpose of this paper, therefore, is to gain a deeper understanding of how to promote change in the coverage of women's sports and female athletes. Specifically, by conducting an expert interview with Kate Fagan, espnW and ESPN journalist, we will examine how the sports media can influence social change in 
women sports, and how collaborations between academia and the sport media can advance future change initiatives.

\section{Industry and Academia}

The following section will examine how espnW provides space for women's sports to be discussed, examined, and consumed which in turn, allows researchers, activist, and industry leaders to collaborate in an effort to promote social change in women's sports.

In recent years, there has been a shift in the way the sport media depicts women's sports. There has not necessarily been more coverage of women's sports, more money devoted toward promoting women's sports, or even more commercialization of women's sports, all of which have been observed on the men's side. However, with the creation of espnW, there is now a specific space, with professional journalism, big media money (i.e., ESPN) and big corporate sponsor backing, in which consumers can have access to the latest commentary on women's sports, specifically those popular in American culture.

According to espnW.com (2015), their mission is as follows:

espnW's mission is to serve women as fans and athletes. espnW.com provides an engaging environment that offers total access to female athletes and the sports they play, takes fans inside the biggest events, and shares a unique point of view on the sports stories that matter most to women.

Some of espnW partners are Nike, Gatorade, P\&G, Oakley, Colavita, and The Women's Sports Foundation. espnW is completely engaged in being the leading entity for women's sports media consumption. They host the espnW: Women + Sports Summit, which can be seen as the most comprehensive and financially supported event of its kind that brings together top athletes (e.g., Kerri Walsh, Billie Jean King, Laila Ali, Abby Wambach), industry leaders (e.g., Adam Silver, Stacey Allaster, Laurel Richie, John Skipper) and other professionals (Kathryn Olson with the Women's Sport Foundation, Dr. Richard Lapchick of the Institute for Diversity and Ethics in Sport).

The before mentioned names (and the many others who have attended the summit), organizations, and brands are all influential producers and consumers of sports. espnW has indeed created a blue ocean for women's sport consumption. Similarly to how ESPN changed the way many people consumed men's sports, espnW has provided women's sports fans a place to enjoy women's sports at the forefront. It is important to note that merely creating a space to consume women's sports, in and of itself, is not enough to ignite social change and eliminate gender bias in women's sports. However, with leadership, gatekeepers, and activist-minded individuals, espnW provides a breeding ground for social change in women's sports.

Gatekeepers are individuals who have connections within a community or industry and can provide special insight or access based on their relationships (Bryman, 2008). Gatekeepers are usually essential for researchers looking to delve deep into a particular industry. Kate Fagan, in particular, has been a vocal and courageous gatekeeper into the culture of sports. Particularly, she has been a voice for women's sports among the giants in men's sports media. Fagan played basketball at 
the University of Colorado. After spending three seasons covering the NBA's 76ers, she joined espnW. Currently, Fagan is a columnist and feature writer for espnW, ESPN.com, and ESPN The Magazine. She has also recently published a memoir entitled, The Reappearing Act, in which she discusses coming out as a lesbian on a nationally ranked college basketball team, where her best friends were devout Christians. Her latest columns have covered: University of Connecticut's historic women's basketball team, Hope Solo's domestic violence issues, Ray Rice and violence in the NFL, and much more. Through the collection of her work, Fagan has made a name for herself as the journalist willing to bring women's sports to the forefront and tackle difficult social issues plaguing sports today.

Fagan's quest to raise awareness of issues in women's sport motivated her to pursue a story on the lack of female coaches in college athletics. While researching the topic, Fagan came across some of Dr. Nefertiti A. Walker's work. Intrigued by the research, Fagan reached out to Walker in 2011. The conversation resulted in Walker sharing a few of her articles on women coaching in men's sports and the glass wall phenomenon (See Walker \& Sartore-Baldwin, 2013) along with data. Fagan went on to use the articles, data, and the conversation to help supplement a thought provoking column with Luke Cyphers entitled, The Glass Wall: Women continue to shatter stereotypes as athletes. So how come they can't catch a break as coaches? (Fagan \& Cyphers, 2012). This was the genesis of Fagan and Walker's academic-industry collaboration. They then went on to serve on a panel together at the 2013 and 2014 espnW Women + Sport Summit, at which they discussed inclusion in sports. Currently, Fagan and Walker are working on a multiyear project entitled Open Look, with espnW and researchers such as E. Nicole Melton, in which they will investigate multiple issues of inclusion in women's sports such as race, sexuality, and gender.

Fagan is unique in the sport media. She continues to tackle difficult issues in women's sport and does so by creating captivating story lines that resonate with a broad audience. She has used an array of techniques to bring awareness to issues in women's sport, which include incorporating scholarly research to help bolster her arguments. Below lies a representation of an interview with Kate Fagan, discussing social change in women's sport and the role industry and academic collaborations play in fostering this change.

\section{The Interview}

Walker: How can the media (or sport journalist) enhance the status of women's sports? How can the media make it more popular?

Fagan: Really simply put, all the media needs to do is cover it. It's not really all that complicated. I think the last time I read up on this topic, $4 \%$ of ESPN's coverage was dedicated to women's sports. So the very basic answer is sports media outlets need to cover more women's sports. There is a blowback that happens when the media covers women's sports. However, I think these comments come from a very small percentage of very loud fans. There is also the idea that women's sports when covered on television, do not get as high ratings as men's sports. However, the low ratings are due mostly 
to the fact that these athletes, coaches and teams' stories are not being told. Viewers are much more interested in sports, when they know the story behind the athlete, the story behind the teams playing. When you turn on an NBA game, you know the story behind the athletes. You know where the athletes have been traded recently, you know the must-see matchups; you know the rivalry between the teams. In women's sports, because of a lack of exposure, the casual fan knows nothing about either team. The casual fan knows very little background information about the players, teams, and coaches, because the media doesn't spend as much time telling stories about women's sports, as they do with the men's sports. So there are a lot of facets that go into why the media doesn't cover women's sports. But if they did spend more time telling the stories that go into the competition of women's sports, it would be interesting to see the outcome.

Walker: It is interesting that you say this, because I can think of when the Olympic Games are on every four years. Fans are really into the female athletes and women's sports. Fans are tuned into the stories of how they got to the Olympics and their competitions. I believe fans are just as interested in the women's sports, as they are the men's sports. Would you agree?

Fagan: Yes, exactly. People care and are invested in sports at any level if they know the storylines and understand the stakes. You can apply this to a youth tee ball game. You become invested in the moment because you know the storyline of your daughter and her team and you know the stakes are that it is important to her. Now all of a sudden that tee ball game becomes much more interesting than if you were just passing by it, unaware of the storyline and stakes. You can apply that to sports all the way through the college and professional ranks. So when you see it at the Olympics, it's similar to the tee ball game. You know the international rivalries and you know the stakes are a gold medal, so you do not need much else to peak your interest. This is what happens day in and day out on the men's side. Anyone who watches sports in the least bit can turn on the television, see the Patriots v. Jets, and know the storylines and understand the stakes in this sort of game because of all the exposure we have had to these storylines over the years. If you pass by a women's sport on television, it just looks like two teams and you do not understand the storylines or stakes. You have no context for it and you have no investment in it. This is why ratings are low and why people do not write about women's sports. It's less about athleticism and dunking, and more about the lack of storylines and understanding of the stakes in women's sports.

Walker: How can the media make women's sports more popular?

Fagan: By telling women's sport stories more often. It begins at the individual grassroots level. For example, I happen to be on television shows and in production meetings. I also happen to pitch women's sport stories more and fight for them more. So maybe we see them on air more when I am involved. This introduces a small amount of women's sports coverage into the conversation. This is how the change in coverage of women's sports is going to happen. 
It's not going to be some miraculous overnight change. Rather, people like me who care about these stories and can write them in interesting ways will change the system little by little. It's never going to be some sweeping, dramatic change. For instance, we thought after the 1999 Women's World Cup, people would now demand more women's sports, since the nation was completely consumed and fell in love with that soccer team. But that did not happen. It will have to be a gradual increase in coverage. So, instead of people just knowing Diana Taurasi and Sue Bird, they now know Brittney Griner and Skyler Diggins because the WNBA took the time to tell their stories. So now maybe they will watch one more game because they know a few more storylines.

Walker: How can journalists address or improve how female athletes have typically been portrayed in the media? (For example, portraying female athletes as sweet and cute/sexy v. skilled and strong/powerful)

Fagan: You know, this trite portrayal of women in the media is not going away any time soon. I think because of social media, blogs, and certain journalists who do portray these women as athletes, and not in stereotypical feminine ways there is a slow change happening. Often times, journalists are given very little time and very little resources to tell the story of a female athlete or women's sport that they are not familiar with in the least bit. They have 600 words and they need to be able to relate to the reader. Therefore, they resort to the ways they have seen women and women's sport stories portrayed. However, there are other journalists like myself who are invested in women's sports, understand women's sports, and can tell the story in an interesting way. There are magazines and other media outlets that are hiring female editors who understand these stories and can tell interesting stories about female athletes and women's sports without falling into the traps of gender stereotypes.

Walker: What changes have taken place, or what are the trends you are seeing in sport media (in terms of reporting women's sport)?

Fagan: To be honest, there hasn't been as much progress as I would have hoped in women's sports. Yes, more girls and women are participating in sports, but this hasn't translated to more coaching positions for women or significantly more women's sports or female athlete stories in the media (with the exception of espnW). We are much further along, but the rest of the world has no idea what's happening in women's sports and what are the critical issues plaguing women's sports.

Walker: Before I get to the next question, when you said, "We, are so much further along,..." who is "we"?

Fagan: We are the people who enjoy women's sports or write about women's sports or cover women's sports or in any way are engaged daily in a conversation about women's sports. We have had critical conversations. We process what's going on with the WNBA and it's players who essentially never have an off-season or negative recruiting in women's college basketball. Whereas 
most people, who are not directly working or participating in women's sports are not thinking about these critical issues. I think we get caught up in thinking that the conversations we are having are being replicated everywhere. I now know different. Since I have been doing a lot more mainstream men's sports in the last six months, my observation has been that they're not (laughs) having these same conversations about women's sports that we discuss. 'They' being anyone who doesn't, for whatever reason, follow women's sports even casually, and that's the majority of people working in and consuming sports.

Walker: Before the espnW (also known as the W) was created do you think that critical conversations about social change were being had, in as big of a space as they are now, in women's sports?

Fagan: Within the general media I would say critical discussions were not being had very frequently. However, we are having these conversations on espnW because whether something we write on the $\mathrm{W}$ is going to be read by a mainstream audience is not the point. The point is that this entity exists, and there is writing about women sports and these stories exist about women's sports. That's why the W was created, to create this space for women's sports to be consumed. Many of these stories on women's sports are read at ESPN. com so that is some progress. These conversations probably are not happening at a lot of other places because they do not have a team of editors, writers and producers whose job is to find and tell the interesting stories in women's sports like at the W. Other places wait for interesting stories that are organically created and then capitalize on the moment, right? Because that's what most media is, it's like occasionally Ronda Rousey will happen and all media outlets will cover that or occasionally the Diana Taurasi kiss will happen and that's just interesting, you can talk about that, people will cover it because it has a hook. But there's a difference between that coverage, sort of reacting to something that organically happens interesting within women's sports and having an entity that's been created solely to discuss and find the interesting stories of women's sports and bring them to the forefront and tell people about issues they may be facing or problems that existed in women's sports. So I think because that place exist now at espnW and with the backing of a bigger company, the branding has a lot of social capital. This certainly doesn't mean that all the stories we put out there are read by the mainstream, but it means that the opportunity is there and the needle is slowly moving in the right direction, if you think that's the right direction.

Walker: Have your received any resistance for writing stories with a critical lens?

Fagan: No. There is very little resistance to me writing critically about sports. I think before the Ray Rice scandal there was some reluctance to write about domestic violence in sports because, this is a crude way to put it, but there was no news hook, right? It was like, we hear this is a problem but, can you just throw a story out there like, 'NFL and domestic violence, they got to get their act together'? The audience isn't going to want to absorb that because they may not understand why it matters or why it is relevant? However, once the 
Ray Rice situation happened, the public gets it and can see why this matters. There is occasionally pushback about wanting to write stories without a news hook, or without an athlete telling the story. But when it comes to just writing about female athletes and trying to get people to think differently about why women's sports is marginalized and trying to debunk some of those myths. . . That has never been a problem at espnW. We have, for the most part, been encouraged to write these types of critical stories.

Walker: Do you think the encouragement to tackle these critical issues is directed to you because you have come to the forefront as the person who can handle critical stories and people are very accepting of you telling a critical story?

Fagan: No. I think there's a tipping point. I think there's a tipping point in that, I've proven myself in being able to write about these stories tactfully. Trying to get important points across, while not being sensational about it. And I think I've proven that I can handle those stories in a way where I can put out an interesting piece while being critical about the topic and sensitive to the issue. But at the same time there's a tipping point. How many of these stories can I do before it becomes, 'oh, that's just what she writes about'? I think that's where I am at, that's where I am right now. Unless I'm just going to become defined by always writing stories about women's marginalization, female athletes, or the struggles women coaches face, it might start to lose its impact because, it can become, 'just things Kate Fagan talks about'. So, yes, there's a tipping point and it's finding that right space. You want to write the important stories that matter, that you're passionate about, and you think people need to hear, but you also do not want them to tune you out, if you're just hitting the same note every time.

Walker: I think you may be unique in addressing critical issues in women's sports and suggesting social change, which can be seen as advocacy. However, you are also one of the few women in your field that demands respect and attention. People pay attention to your opinions about football, basketball, whatever sport you may be covering. Do you feel like you have to balance being a journalist and making a call for social change in women's sports?

Fagan: I'll try to make a larger point in answering this question. An issue I see in women's sports is that the people who might be best at their jobs, and I'm not talking about coaching here, I mean like a marketing director at the WNBA or PR person is not planning to make a home in women's sports. A lot of times it's a pit stop until they can move over to the NBA side and you see this all the time. You see that a lot of people who work for teams will work for the WNBA franchise and it's almost like a promotion to work for the NBA franchise. What ends up happening if you work specifically at the WNBA is that they often lose their most creative, interesting people to higher profile sports. Therefore, the WNBA for instance, is in a tough spot. Of course there are exceptions. However, often the talent that could make the WNBA relevant or better storytelling-wise, the ones who have cool marketing ideas, and can get 
the brand more recognition, they (e.g., WNBA) will end up losing them, and other sports (e.g., high profile men's sports) will gain these valuable employees. Thereby, becoming a self-fulfilling prophecy. The same thing happens in the media world. If I've proven that I write well, or have interesting opinions about women's sports, people recognize this. It is never said, but it is suggested that, you've proven yourself as being interesting and smart so let's not, "waste" it on talking about things that don't move the needle, so to speak. So you end up having your best storytellers and maybe your most insightful people eventually covering and working with men's sports, because that's how they can make more money, and that's where they can get more exposure. They start talking about the sports that reinforce the mainstream again. So, that's what I see happening a lot in women's sports.

I'm not sure whether I need to balance them. I want to be able to balance them and it's important to me, but I must also consider how can I be most valuable to my company? Do I, like everyone else, want to maximize my salary options? Many times in my field, talking about the Denver Broncos is more valuable to your company than saying something smart about women's field hockey. So, where do you put your energy and how do you make sure you are still being true to yourself and be able to talk about the interesting things and the social issues that you care about? This is what I have to weigh in my work. However, at this point, I don't worry about whether I write too many critical social issue pieces. I feel like I cannot write enough about this stuff because these critical stories are so interesting and have so many layers to them. I take my job day by day and try to write the most interesting story on the topic I am tasked to write about, while continuing to advocate for women's sports and stories when I have the opportunity to do so.

Walker: What are your thoughts on the impact of partnerships between academia and practitioners in promoting change in women's sport?

Fagan: I think they're really important because sometimes when you're trying to talk about women's sports and you're trying to get people to see things from a different perspective it is difficult. If you just argue with storytelling and anecdotes, they will say, 'you're biased' or 'yeah, you played college basketball, that's why you would have this perspective'. But I think if you can, for women's sports, be able to partner with academia and do interesting research, have data, numbers, and projects that are at least attempting to strip away any sort of personal biases it can help create awareness and develop social change. You now have data to say 'no, look at this marketing research that says sex doesn't sell women's sports, authenticity sells'. To be able to package it in a very tightly knit story supported by data are really important at this stage of women's sports. So, that partnership to me is invaluable because you really need academia and research support to be able to change minds and be able to point to data, research, and have academia support which feels more clinical in people's minds, than a person telling a story.

Walker: What are some of the ways you feel academics could support your industry? 
Fagan: Academics and researchers can support the sport media industry by continuing to do really interesting and revealing studies and providing data for our stories. We do a pretty good job of getting the stories of athletes, coaches, and examining the sports world. But academics provide solid data that is very useful to journalists. Sometimes I don't even know most of this research on women's sports exists. And I don't know how you remedy that. I imagine there is all kinds of research and all kinds of numbers that will support all kinds of different arguments for women's sports that I have no clue even exists. The only reason I'm even knowledgeable about a small fraction of these type of things is because of our relationship that we have developed over the past few years and because certain panels I've done has opened doors to allow me to be in spaces where I'm going to hear about critical research on women's sports. I don't know if it is possible but spaces need to be created for academic and industry collaborations toward social change in women's sports. espnW has done a good job trying to partner with researchers to bring this critical research to light. I think the biggest challenge to me is being aware of what has been done already and making sure that someone can synthesize it to digestible content for mainstream consumers. This is a huge gap in academic research helping inform industry practice and making significant changes in women's sports.

Walker: Through your talented writing and the unique niche of blending academic research, excellent storytelling, and a critical lens, you have undoubtedly become a voice for social change in women's sports. To name a few, you have covered issues such as the homophobic culture in college athletics, the unfair dismissal of coaches influenced by gender and sexual orientation, and violence against women in sports.

What are some of your closing thoughts on women's sports progressing through collaborations between journalists and academic researchers?

Fagan: I think that if you can develop the model that you and I have, and the way we have been able to disseminate interesting and popular stories that are researched and backed on the academic side by data, it makes for a very powerful piece of work. I think it is very powerful when someone can read a story that I write that is interesting and it is backed by data and your research, it makes for a convincing perspective. It is also something that people are not used to seeing in sports. If people can replicate this model that we have built 50 times around the country, the model where you have a journalist write interesting stories, supported by an academic researcher's data, then progress and change can take place. The worst thing someone can do is write a story about a female athlete or women's sport and it be cliché and boring, because then it confirms naysayers' notion of women's sports. If we can have more academic researchers connect with sport writers at places like the espnW Summit or NCAA Women's Basketball Final Four, or other places where us sport writers congregate, we could get more collaborations moving forward. For instance, at the NCAA Women's Basketball Final Four, I ran into Dr. Jami Lobpries, a sport management professor at the University of Tampa, she began to discuss her research on individual athlete branding and we got deep into conversation on the topic. 
If I have an interesting story about female athlete branding, I will reach out to her for ideas and thoughts on the topic. This is how these relationships begin and turn into collaborations like you and I have with espnW's inclusion project, the Open Look. These collaborations with academics change the way us journalists think about sport and influences the stories we tell.

\section{Conclusions}

The purpose of this paper was to gain a deeper understanding of how to promote change in the coverage of women's sport and female athletes. Through an expert interview with Kate Fagan, espnW and ESPN journalist, we examined how the sport media can influence social change in women sport, and how collaborations between academia and the sport media can advance future change initiatives. Note that these ideas are not new, as a number of scholars have argued research is likely to create more meaning and have a greater impact when scholars and practitioners work together through the research process. At times, though, it seems as if these collaborations are simply a way for one side to tell the other that they are taking the wrong approach or focused on inconsequential issues. Scholars, for instance, share their findings in an earnest attempt to inform managerial and marketing practices in the sport industry. Practitioners read these conclusions, reflect on their work experiences, and then honestly and respectfully tell academics they need to get a clue (for a more eloquent account of this dynamic see Cunningham, 2012).

A slightly more advantageous partnership develops when researches articulate ways they can help practitioners (e.g., provide empirical data related to program effectiveness, see Welty Peachey, 2015), or when practitioners recognize the importance of research and actively search for scholars who can assist their efforts ( similar to how Kate Fagan initially solicited the advice of Dr. Nefertiti A. Walker). Unfortunately, the partnership often ends at this point; such that researchers have the information they need for career and publication purposes, and practitioners can include the empirical data in future grant proposals. Though both parties benefit, the potential to create social change drastically increases when scholars engage in the research process together. The relationship between Walker and Fagan demonstrates as much. After the initial collaboration, they presented their work at a practitioner-oriented conference (i.e., espnW Women + Sport Summit) and continued discussing issues related to women in sport. This prolonged engagement has inspired new, collaborative research projects that include additional researchers and practitioners.

While some scholars may read this article and be inspired to seek out industry partnerships, others may question the likelihood of similar relationship forming in the future. Such skepticism is not without merit as collaborations are relatively rare in many academic fields, and Fagan's desire to incorporate scholarly research is somewhat unique compared with her peers. Nevertheless, the preceding interview provides needed insight into the practitioner prospective, which can assist academics in their efforts to establish meaningful collaborations. First, practitioners will seldom turn to SPORTDiscus or other scholarly databases when searching for information. As such, researchers must continue to find ways to disseminate 
new knowledge to practitioners and activists. A number of scholars have worked toward this goal by discussing relevant research and topics in personal blogs, such as George Cunningham (Diversity in Sport Blog), Pat Griffin (LGBT Sport Blog), Nicole LaVoi (One Sport Voice), Erin Buzuvis and Kristine Newhall (Title IX Blog). Others, such as Mary Hums and Eli Wolff, share their projects and research with mainstream media outlets that cover a number of issues. Several of these authors also share their insights and activities on social media to reach a broader audience. While these efforts make information more available, it does not guarantee that industry professionals will access the information. A way researchers can increase readership is by generating knowledge that is primarily intended for a practitioner audience. As one illustrative example, the Tucker Center in the University of Minnesota, publishes The Women Coaches Research Series and Report Card to help "increase the percentage of women in the coaching profession, provide an institutional accountability mechanism, create awareness, and start a national dialogue" on the steady decline of female coaches at the collegiate level. The findings are concise, relevant, and use eye-catching charts and figures that are visually appealing to layperson and scholar alike.

In addition, scholars and practitioners can promote knowledge sharing by creating opportunities for engagement. For example, the Mark H. McCormack Department of Sport Management at the University of Massachusetts-Amherst has worked toward this goal by hosting Executives in Residence and Sport Talk panel discussions that include perspectives from executives, practitioners, advocates, and scholars. These panels are live-steamed on the Internet and allow viewers to submit questions via Twitter, thereby creating an environment where multiple voices can be heard. In addition, researchers and practitioners can attend similar conferences. In some instances, conferences are designed with the purpose of bringing scholars, activists, and practitioners together so they can share ideas and engage in constructive dialogues (e.g., Muhammad Ali Center Athletes and Social Change Forum). However, it is also beneficial to attend practitioner-oriented conferences. As the interview with Fagan suggests, both presentations (i.e., Walker at the espnW Women + Sport Summit) and casual conversations (i.e., Lobpries at the Women's Basketball Final Four) generate interesting questions and lead to future collaborations.

In sum, this article demonstrates that social change in women's sports can be aided by collaboration among all invested stakeholders. The Open Look project, which is a multiyear research project investigating the culture of inclusion in college athletics, could not take place without the influential power of ESPN and espnW, the artful storytelling of a journalist like Kate Fagan, or the researching skills of academics. In this instance, all parties are working together to make sports a more inclusive culture. This collaboration between academia and industry is essential for social change. Through the Open Look project, we will soon have a comprehensive understanding of inclusion in college athletics. Not only has Kate Fagan been able to produce critical articles through her talks and collaborations with academic researchers, but also academic researchers have been inspired to investigate studies based on her industry insight. Often times, academics work within a silo, getting caught up in the cycle of publish or perish. Likewise, those in sports media can get caught up in reproducing gender biased stories that favor men's sports over women. Journalists can lose sight of their critical lens, while trying to produce stories that can grab the majority, causal sport fan's attention. 
However, when sports professionals like Kate Fagan, coupled with sports media giants like ESPN, join forces with academic researchers, a meaningful impact toward change can take place.

\section{References}

Angelini, J.R. (2008). Television sports and athlete sex: Looking at the differences in watching male and female athletes. Journal of Broadcasting \& Electronic Media, 52, 16-32. doi:10.1080/10934520701820752

Bryman, A. (2008). Social research methods. New York: Oxford University Press.

Burch, L., Eagleman, A.N., \& Pedersen, P.M. (2012). Gender and nationalism in the 2010 Winter Olympics: An examination of online media coverage. International Journal of Sport Management, 13, 1-17.

Caple, H., Greenwood, K., \& Lumby, C. (2011). What League? The Representation of Female Athletes in Australian Television Sports Coverage. Media International Australia, 140, 137-146.

Clavio, G., \& Eagleman, A.N. (2011). Gender and sexually suggestive images in sports blogs. Journal of Sport Management, 25, 295-304.

Cooky, C., Messner, M.A., \& Hextrum, R.H. (2013). Women play sport, but not on TV: A longitudinal study of televised news media. Communication and Sport, 1, 203-230. doi:10.1177/2167479513476947

Cunningham, G.B. (2012). Bridging the gap: Researchers and activists pursuing LGBT equality in sport. In G.B. Cunningham (Ed.), Sexual orientation and gender identity in sport: Essays from activists, coaches, and scholars. College Station, TX: Center for Sport Management Research and Education.

Daniels, E.A., \& Wartena, H. (2011). Athlete or sex symbol: What boys think of media representations of female athletes. Sex Roles, 65, 566-579. doi:10.1007/s11199-0119959-7

Entman, R.M. (1993). Framing: Toward clarification of a fractured paradigm. The Journal of Communication, 43, 51-58. doi:10.1111/j.1460-2466.1993.tb01304.x

espnW. (2015). espnW. Retrieved March 1, 2015 from http://espn.go.com/espnw/about.

Fagan, K., \& Cyphers, L. (2012). The glass wall: Women continue to shatter stereotypes as athletes. So how come they can't catch a break as coaches? Retrieved March 1, 2015, from http://sports.espn.go.com/espn/eticket/story?page=theGlassWall\& src $=$ mobile.

Fink, J.S. (2014).Female athletes, women's sports, and the sport media commercial complex: Have we really "come a long way, baby"? Sport Management, Review.

Fink, J.S. (2013). Theory development in sport management. My process and other considerations. Sport Management Review, 16, 17-21. doi:10.1016/j.smr.2011.12. 005

Fink, J.S. (2010, June). Using athletes to advertise their sport: A comparison of male and female athletes and the notion that "sex sells". Paper presented at the meeting of the North American Society for Sport Management, Tampa, Miami, FL.

Frisby, W., Reid, C.J., Millar, S., \& Hoeber, L. (2005). Putting "participatory” into participatory forms of action research. Journal of Sport Management, 19, 367-386.

Greer, J.D., Hardin, M., \& Homan, C. (2009). "Naturally" less exciting? Visual production of men's and women's track and field coverage during the 2004 Olympics. Journal of Broadcasting \& Electronic Media, 53, 173-189. doi:10. 1080/08838150902907595

Irwin, R.L., \& Ryan, T.D. (2013). Get real: Using engagement with practice to advance theory transfer and production. Sport Management Review, 16, 13-16. doi:10.1016/j. smr.2011.12.007 
Kane, M.J. (2013). The better sportswomen get, the more the media ignore them. Communication and Sport, 3, 231-236. doi:10.1177/2167479513484579

Kian, E.M., Mondello, M., \& Vincent, J. (2009). ESPN - The women's sport network? A content analysis of Internet coverage of March Madness. Journal of Broadcasting \& Electronic Media, 53, 477-495. doi:10.1080/08838150903102519

Kian, E.M., Vincent, J., \& Mondello, M. (2008). Masculine hegemonic hoops: An analysis of media coverage of March Madness. Sociology of Sport Journal, 25, 223-242.

Lumpkin, A. (2009). Female representation in feature articles published by Sports Illustrated in the 1990s. Women in Sport and Physical Activity Journal, 18, 38-51.

Van de Ven, A.H. (1989). Nothing is quite so practical as a good theory. Academy of Management Review, 14, 486-489. doi:10.5465/AMR.1989.4308370

Walker, N.A., \& Sartore-Baldwin, M.L. (2013). Hegemonic masculinity and the institutionalized bias toward women in men's collegiate basketball: What do men think? Journal of Sport Management, 27, 303-315.

Welty Peachey, J. (2015). Creating social change in and through intercollegiate sport: State of the field, challenges, and future directions. Journal of Intercollegiate Sport. 